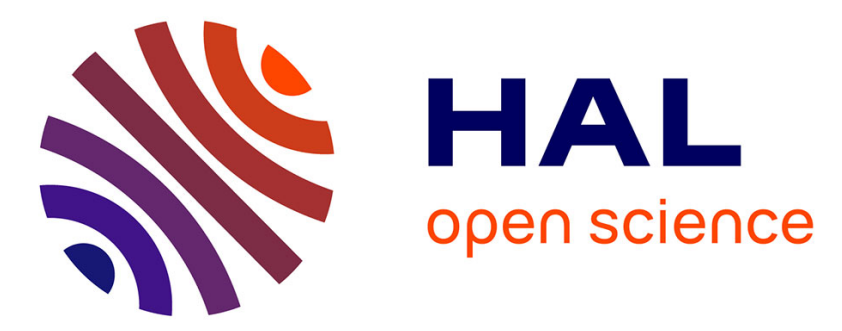

\title{
Thermal behaviour of high-temperature superconducting fault current limiters: Application to
}

\author{
J.A. Lorenzo-Fernández, M.R. Osorio, J.A. Veira, M.J. Tello, F. Vidal
}

\section{To cite this version:}

J.A. Lorenzo-Fernández, M.R. Osorio, J.A. Veira, M.J. Tello, F. Vidal. Thermal behaviour of hightemperature superconducting fault current limiters: Application to. Journal of Physics and Chemistry of Solids, 2010, 71 (8), pp.1105. 10.1016/j.jpcs.2010.03.015 . hal-00661912

\section{HAL Id: hal-00661912 \\ https://hal.science/hal-00661912}

Submitted on 21 Jan 2012

HAL is a multi-disciplinary open access archive for the deposit and dissemination of scientific research documents, whether they are published or not. The documents may come from teaching and research institutions in France or abroad, or from public or private research centers.
L'archive ouverte pluridisciplinaire HAL, est destinée au dépôt et à la diffusion de documents scientifiques de niveau recherche, publiés ou non, émanant des établissements d'enseignement et de recherche français ou étrangers, des laboratoires publics ou privés. 


\section{Author's Accepted Manuscript}

Thermal behaviour of high-temperature superconducting fault current limiters: Application to microlimiters

J.A. Lorenzo-Fernández, M.R. Osorio, J.A. Veira, M.J. Tello, F. Vidal

PII: S0022-3697(10)00061-2

DOI: doi:10.1016/j.jpcs.2010.03.015

Reference: PCS 6124

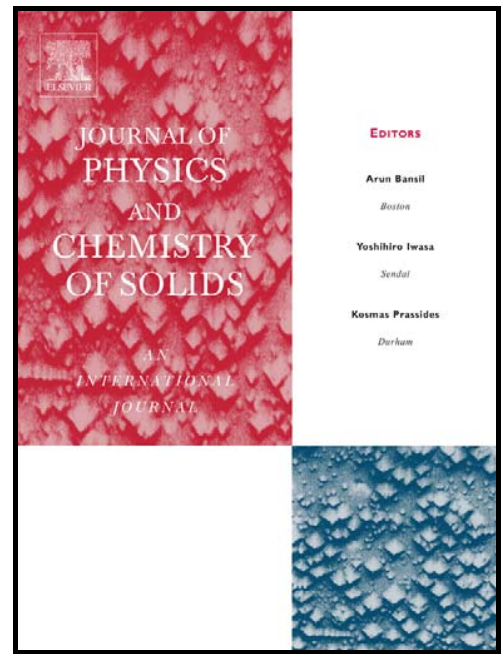

www.elsevier.com/locate/jpcs

To appear in: $\quad$ Journal of Physics and Chemistry of Solids

Cite this article as: J.A. Lorenzo-Fernández, M.R. Osorio, J.A. Veira, M.J. Tello and F. Vidal, Thermal behaviour of high-temperature superconducting fault current limiters: Application to microlimiters, Journal of Physics and Chemistry of Solids, doi:10.1016/j.jpcs.2010.03.015

This is a PDF file of an unedited manuscript that has been accepted for publication. As a service to our customers we are providing this early version of the manuscript. The manuscript will undergo copyediting, typesetting, and review of the resulting galley proof before it is published in its final citable form. Please note that during the production process errors may be discovered which could affect the content, and all legal disclaimers that apply to the journal pertain. 


\title{
Thermal behaviour of high-temperature superconducting fault current limiters: Application to microlimiters.
}

\author{
J. A. Lorenzo-Fernández ${ }^{1,2}$, M. R. Osorio ${ }^{1}$, J. A. Veira ${ }^{1}$, M. J. Tello ${ }^{2}$, F. Vidal ${ }^{1}$ \\ ${ }^{1}$ LBTS, Departamento de Física da Materia Condensada, Universidade de Santiago de Compostela, E15782, Spain \\ ${ }^{2}$ Departamento de Física de la Materia Condensada, Facultad de Ciencia y Tecnología, Universidad del País Vasco, Bilbao \\ E48080, Spain
}

\begin{abstract}
Fault current limiters are one of the most promising applications of high-temperature superconductors. Two important and interrelated aspects of these devices are their thermal behaviour and their refrigeration. Here we will present some results of our recent researches about this topic concerning the possibility of using superconducting thin-film microbridges as very efficient microlimiters intended to operate at very low powers as could be superconducting microelectronics applications (SQUID based electronics, infrared detectors, etc.).
\end{abstract}

Key words: Fault current limiters, microlimiters, thin films, refrigeration. PACS: 85.25.-j, 74.72.-h,74.78.-Bz

Superconducting fault current limiters (SFCL) based on high temperature superconductors (HTSC) of different types, inductive, resistive or hybrid (i.e. inductive-resistive), have being extendedly studied $[1,2,3,4,5,6,7]$. The refrigeration and thermal behaviour of the superconducting elements are aspects of crucial importance for the overall performance of these devices. Thin film samples present several advantages to be used in current limiting applications $[4,8,9]$. We have studied the use of this kind of samples in two up to now nearly unexplored configurations. One is a hybrid limiting device based on meandered HTSC thin-films refrigerated by using a thermoacoustic refrigerator [10], and the other a resistive FCL based on "thermally small" superconducting microbridges [9] intended to operate at very low powers (SQUID based electronics, infrared detec-

Email address: felix.vidal@usc.es (F. Vidal ${ }^{1}$ ) tors, etc.). In this work we will summarize some of our recent results on this last issue.

In figure 1 we show a typical electric field versus current density $(E-J)$ curve, corresponding to one of the microbridges (denoted BS7) used in our experiments. This microbridge, whose length, width and thickness are, respectively, $385 \mu \mathrm{m}, 28 \mu \mathrm{m}$ and $300 \mathrm{~nm}$, and with $T_{c}=88.6 \mathrm{~K}$, has been grown on a sapphire substrate. The two characteristic current densities are indicated in this figure: The critical, $J_{c}$, at which dissipation first appears, and the so-called supercritical, $J^{*}$, at which the microbridge is triggered into highly dissipative states. Let us note here that we have chosen for our studies microbridges of these dimensions to guarantee a good thermal behaviour before, during and after the current fault, as we will see below. In addition, the widths of our microbridges are well above the threshold at which $J^{*}$ is sample-width dependent [11]. The strong increase of $E$ for current densities around $J^{*}$ make this type of 
samples very useful for FCL. However, the current is effectively limited only for electric fields or, equivalently, applied voltages well above that at which the limiter is triggered from normal operation (sample in the superconducting state) to current fault mode. In addition, once $J^{*}$ is attained, a thermal runaway $[12,13]$ can be provoked which causes the reduction of the circulating current well below the nominal value (i.e., the current in normal operation without a fault) or very important damage on the microbridge (that can be even burnt out).

The superconducting microbridge exchanges heat mainly with its substrate, because at the operation temperatures, around $90 \mathrm{~K}$, the heat transfer coefficient between YBCO films, for instance, and their substrate is $h_{b s} \approx 10^{3} \mathrm{Wcm}^{-2} \mathrm{~K}$, whereas through liquid nitrogen or between the substrate and the copper holder they are 1000 times less $[9,14,15]$. Hence, the conditions for a good refrigeration and, therefore, an optimal operation of the limiting device, depend very much on the relative dimensions of the microbridge and their substrate. The optimal refrigeration should allow us to operate with the minimum microbridge temperature increment relative to that of the bath, $\Delta T_{b}$. If the Biot number $[9,16]$ of both the microbridge and its substrate are $B i \ll 1$ and, simultaneously, the thermal diffusion length, $L_{t h}$, is longer than the corresponding thickness, $\Delta T_{b}$ may be crudely approached by

$$
\Delta T_{b}=e_{b} J E\left(\frac{1}{h_{b s}}+\frac{A_{b}}{A_{s}} \frac{1}{h_{s r}}\right),
$$

where $e_{b}$ is the microbridge thickness, $A_{b}$ and $A_{s}$ are the surface areas of the superconductor bridge and, respectively, its substrate. As $h_{b s} \gg h_{s r}, \Delta T_{b}$ will directly depend on $A_{b} / A_{s}$, the condition of "thermal smallness" being,

$$
\frac{A_{b}}{A_{s}}<\frac{h_{s r}}{h_{b s}}
$$

under which $\Delta T_{b}$ approaches its "intrinsic" value, which is the temperature increase just associated with the effective thermal resistance of the interface bridge-substrate. For our microbridges similar to BS7 and under faults with characteristic times above 10 ms (of the order of commercial ac current periods), the conditions, $B_{i} \ll 1$ and $L_{t h}>e$ fully apply. In addition, as $A_{b} / A_{s} \approx 4 \times 10^{-4}$ whereas $h_{s r} / h_{b s} \approx$ $10^{-3}$, this microbridge is "thermally small". One may use equation 1 to estimate $\Delta T_{b}$ when the microbridge is in stationary conditions under currents just below $J^{*}$. From figure 1, the power density involved is around $5 \times 10^{6} \mathrm{~W} / \mathrm{cm}^{3}$ which leads, by also using the appropiate parameter values ${ }^{1}$, to $\Delta T_{b} \approx 0.1$ $K$. Even for faults involving powers ten times higher than those considered above, $\Delta T_{b}$ will remain below 1 $K$. One may also use equation 1 to roughly estimate that if the superconducting bridge had $A_{b} / A_{s}$ one thousand times larger, as it is the case of those currently proposed for high power applications [1, 17], $\Delta T_{b}$ would take values at least two orders of magnitude higher. To confirm these values at a quantitative level, $\Delta T_{b}$ has been calculated by using a finite element method similar to the one described in [13]. Under the same conditions as above, for the BS7 microbridge we found again $\Delta T_{b} \approx 0.1 \mathrm{~K}$.

In the case of $\mathrm{SrTiO}_{3}$ substrates, which have relatively poor thermal conductivities, the condition $B i \ll 1$ does not apply anymore. Therefore, a term proportional to $1 / k_{s}$ (i.e. to the thermal conductivity of the substrate) must be added in equation 1 . For microbridges under the same conditions as before, this leads to $\Delta T_{b} \approx 2 \mathrm{~K}$, a value that is confirmed by using the finite element method commented above. Let us stress, finally, that for a bridge on sapphire but having a surface relative to that of its substrate one thousand times larger, the finite element method yields $\Delta T_{b} \approx 50 \mathrm{~K}$.

To probe a microlimiter with low thermal dimensions, we have implemented the electrical circuit schematized in the inset of figure 1 , with the microbridge BS7 as $R_{b}$ connected in series to the variable load resistance $R_{L}$, this last one representing the impedance of the circuit to be protected. The measurements were made in a cryostat with the sam-

\footnotetext{
${ }^{1}$ The substrate thermal conductivities $\left(K_{s}\right)$ and heat capacities $\left(C_{s}\right)$ are of the order of $10 \mathrm{~W} / \mathrm{cm} \mathrm{K}$ and $0.6 \mathrm{~J} / \mathrm{cm}^{3}$ $\mathrm{K}$ for sapphire, and $0.2 \mathrm{~W} / \mathrm{cm} \mathrm{K}$ and $1 \mathrm{~J} / \mathrm{cm}^{3} \mathrm{~K}$ for $\mathrm{SrTiO}_{3}$, whereas for YBCO bridges $K_{b} \approx 0.05 \mathrm{~W} / \mathrm{cm} \mathrm{K}$ and $C_{b} \approx 0.7$ $\mathrm{J} / \mathrm{cm}^{3}$ K. See, e. g., Refs. [14, 15, 16].
} 


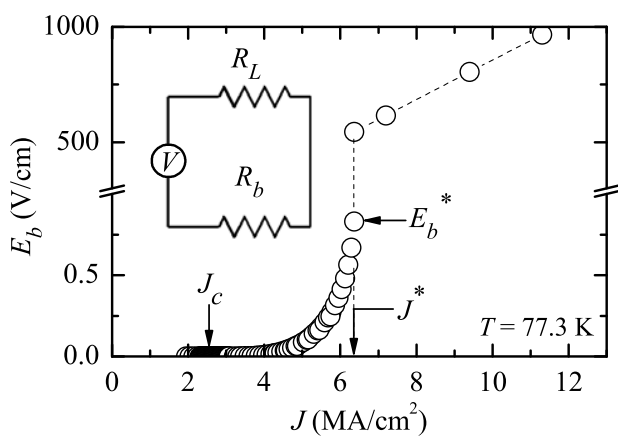

Figure 1: A typical $E-J$ curve obtained at $T=77.3 \mathrm{~K}$ in one of the microbridges used in our experiments (BS7). The inset shows a schematic diagram of the circuit used to probe how the microbridge acts as a FCL, protecting the load resistance, $R_{L}$, from a voltage fault. Figure from Ref. [9].

ple submerged in a forced flow of helium gas. The temperature of the copper holder of the microlimiter was measured with a platinum thermometer and regulated with an electronic system which ensures a temperature stabilization better than $0.05 \mathrm{~K}$. Two examples of the $I-V$ curves obtained in this $R_{L}-R_{b}$ circuit (with $R_{L}=4.9 \Omega$, this value taking already into account the resistance of the circuit electrical wires, of the order of $1.9 \Omega$ ) by using the electronic system described elsewhere $[11,12]$ are shown in figure 2. In these curves the voltage was imposed and acquired during pulses of $1 \mathrm{~s}$, a time much longer than the one needed by the microlimiter to reach the stationary state. The bath temperatures were 81.9 $\mathrm{K}$ (circles) and $85.0 \mathrm{~K}$ (triangles). As below $V^{*}$ the flux-flow resistance of the microbridge remains much lower than $R_{L}$, both curves are almost linear up to $V^{*}$. Together with the low heating estimated above, this quasi-ohmic behavior is crucial to allow the microlimiter to work just below $V^{*}$ under stationary conditions and without disturbing the circuit to be protected.

The results presented in figure 2 also illustrate two other central aspects of the microbridges when working as FCL. Note first that, once the source voltage overcomes $V^{*}$, the current in the circuit varies quite slowly even up to voltage faults as important as four

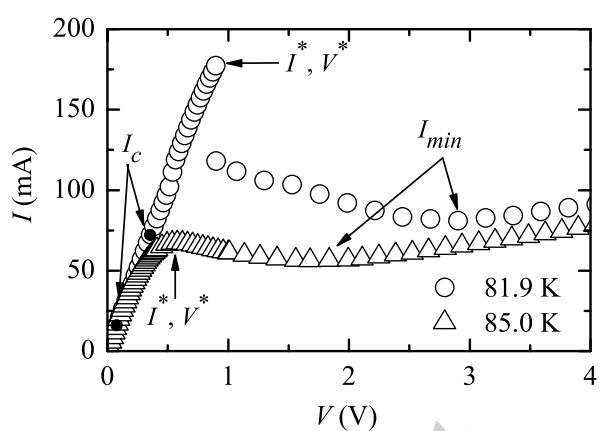

Figure 2: Two $I-V$ curves, showing their strong bath temperature dependence, of the $R_{L}-R_{b}$ circuit schematized in the inset of figure 2 In these examples $R_{b}$ is the microbridge BS7 and $R_{L}=4.9 \Omega$. Figure from Ref. [9].

times $V^{*}$, the current taking a minimum value, $I_{m i n}$, at some (temperature-dependent) voltage. Moreover, the sharp drop at $V^{*}$ of the current is also temperature dependent, being almost absent in the curve at $85.0 \mathrm{~K}$. Both aspects are related and may be explained in terms of the approaches based on the propagation of self-heating hot spots $[18,19,20]$ : Above $V^{*}$ part of the microbridge becomes normal and then, as the total voltage of the circuit is fixed, the resistance increase originates a current decrease up to the minimum current, $I_{\min }$, capable of sustaining the normal zone. If the fault voltage increases, the hotspot length will grow accordingly, keeping the current roughly constant. At a quantitative level, both aspects may be easily explained by just taking into account the reduced temperature $\left(T / T_{c}\right)$ dependence of $I^{*}$ and $I_{\min }$,

$$
I(T)=I(0)\left(1-\frac{T}{T_{c}}\right)^{n},
$$

with $n=3 / 2$ for $I^{*}[11,12]$ and $1 / 2$ for $I_{\text {min }}$ $[18,19,20]$. Therefore, if the reduced temperature increases both the discontinuity at $V^{*}$ and the ratio $I^{*} / I_{\min }$ will decrease, in agreement with the results of figure 2 The "optimal" reduced temperature for the microlimiter operation, $T_{o p} / T_{c}$, will be then given by the condition $I^{*}\left(T_{o p}\right)=I_{\min }\left(T_{o p}\right)$. By using equa- 
tion 3 , this leads to,

$$
\frac{T_{o p}}{T_{c}}=1-\frac{I_{\min }(0)}{I^{*}(0)} .
$$

At $T_{o p}$ the current limited during the voltage fault will be roughly equal to the nominal one. As $I_{\min }(0)<I^{*}(0), T_{o p}$ will be near, but below enough, $T_{c}$ to make $I^{*}\left(T_{o p}\right)$ adequate for the practical operation of the microlimiter under such an optimal temperature.

The above results, experimentally confirmed with our studies [9], allow us to "thermally tune" a superconducting microlimiter for an optimal protection. The results summarized in figure 3 were measured by using a circuit similar to that of the inset of figure 1. In these examples, $R_{S}$ is again the BS7 microbridge and $R_{L}=51.2 \Omega$ (taking into account the resistance of the circuit electrical wires). For the curve measured at $83.0 \mathrm{~K}$, the applied voltage was $5.8 \mathrm{~V}$ before $\left(t_{1}\right)$ and after $\left(t_{2}\right)$ a fault regime of $9.5 \mathrm{~V}$. For the curve at $85.0 \mathrm{~K}$, which is near $T_{o p}$, these values were $3.5 \mathrm{~V}$ and $7.5 \mathrm{~V}$, respectively. As expected, the protection is excellent, whereas there is an overprotection when working well below $T_{o p}$. In both cases the recovery after the fault is achieved under current. This is another considerable practical advantage when compared to the superconducting limiters used in high power applications $[1,17]$. These results suggest that optimal current limitation in superconducting electronics could be accomplished by the own conductive pathways after a proper design (e. g. by decreasing the width of the pathway at well refrigerated selected locations), thus improving compactness.

We have summarized some of our works on the thermal behaviour and the refrigeration of fault current microlimiters based on HTSC thin-film microbridges. Our results indicate that by using the appropriate substrates and the right ratio microbridgeto-substrate area it is possible to operate in a regime where a relative small fault provokes their transition to highly dissipative states that strongly increase the limitation efficiency. This opens then a promising application of these microlimeters in microelectronics based on HTSC materials.

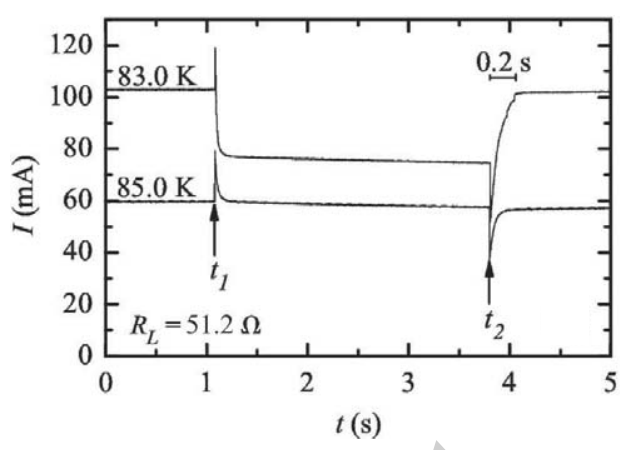

Figure 3: Two examples of the time evolution of the current measured in presence of voltage faults between $t_{1}$ and $t_{2}$. Figure from Ref. [9].

This work has been supported by the Spanish Ministerio de Educación y Ciencia (Grant No. FIS2007-63709), and the Xunta de Galicia (Grant No. PGIDIT04TMT206002PR).

\section{References}

[1] M. Noe and M. Steurer, Supercond. Sci. Technol. 20 (2007) R15-R29

[2] V. Sokolovsky, V. Meerovich, I. Vajda, V. Beilin, IEEE Trans. Appl. Supercond. 14 (2004) 199000

[3] W. Paul, M. Chen, M. Lakner, J. Rhyner, D. Braun and W. Lanz, Phys. C 354 (2001) 27-33

[4] L. Antognazza, M. Decroux, S. Reymond, E. de Chambrier, J.-M. Triscone, W. Paul, M. Chen, Ø. Fischer, Physica C, 372-376 (2002) 1684-7

[5] M. Decroux, L. Antognazza, S. Reymond, W. Paul, M. Chen, and Ø. Fischer, IEEE Trans. Appl. Supercond., 13 (2003) 1988-91

[6] M. R. Osorio, L. Cabo, J. A. Veira and F. Vidal, Supercond. Sci. Technol. 17 868-75

[7] M. R. Osorio, J. A. Lorenzo Fernández, J. A. Veira and F. Vidal, Supercond. Sci. Technol. 21 (2008) 095011 
[8] M. R. Osorio, J. A. Lorenzo, P. Toimil, G. Ferro, J. A. Veira and F. Vidal, IEEE. Trans. Appl. Supercond. 16 (2006) 1937-42

[9] J. A. Lorenzo, M. R. Osorio, J. A. Veira and F. Vidal, Supercond. Sci. Technol. 22 (2009) 025009

[10] M. R. Osorio, A. Bétrancourt, M. X. François, J. A. Veira and F. Vidal, Supercond. Sci. Technol. 21 (2008) 095013

[11] M. Ruibal, G. Ferro, M. R. Osorio, J. Maza, J. A. Veira, and F. Vidal, Phys. Rev. B. 75 (2007) 012504

[12] J. Viña J, M. T. González, M. Ruibal, S. R. Currás, J. A. Veira, J. Maza, and F. Vidal, Phys. Rev. B68 (2003) 224506, and references therein.

[13] J. Maza, G. Ferro, J. A. Veira and F. Vidal, Phys. Rev. B. 78 (2008) 094512

[14] J. Mosqueira, O. Cabeza, M. X. François, C. Torrón, and F. Vidal, Supercond. Sci. Technol. 6 (1993) 584-8

[15] J. Duron, F. Grilli, L. Antognazza, M. Decroux, B. Dutoit, and $\varnothing$ Fisher, Supercond. Sci. Technol. 20 (2007) 338-44

[16] See e. g., A. J. Chapman, 1984 Heat Transfer (New York: MacMillan Publishing Company) chap 4

[17] See e. g., Proceedings of the NATO Advanced Study Institute 2000 Applications of Superconductivity (NATO Asi Series E-365) ed Weinstock $\mathrm{H}$ (Dordrecht: Kluwer Academic Publishers) p 247-415.

[18] W. J. Skocpol, M. R. Beasley, and M. Tinkham, J. Appl. Phys. 45 (1974) 4054-66

[19] See e. g., A. VI. Gurevich, and R. G. Mints, Rev. Mod. Phys. 59 (1987) 941-99

[20] G. D. Poulin, J. Lachapelle, S. H. Moffat, F. A. Hegmann, and J. S. Preston, Appl. Phys. Lett. 66 (1995) 2576 